\title{
Формирование фотодиодов на основе p-n переходов в слоях ГЭС КРТ МЛЭ для спектрального диапазона 8-11 мкм.
}

\author{
М.В. Якушев, В.С. Варавин, И.В. Сабинина, Г.Ю. Сидоров, Д.В. Марин, А.В. Предеин, С.А. \\ Дворецкий, В.В. Васильев, Ю.Г. Сидоров, А.В. Латышев, \\ Институт физики полупроводников им. А.В.Ржанова СО РАН, \\ Новосибирск, 630090, пр. Ак. Лаврентьева, 13
}

эл.nочma: vas@isp.nsc.ru

DOI 10.34077/RCSP2019-62

Разработаны основы технологических процессов изготовления $\mathrm{p}$ - $\mathrm{n}$ переходов с использованием процесса имплантации ионов $\mathrm{As}^{+}$с последующими активационным и восстанавливающим отжигами. По этой технологии были изготовлены экспериментальные образцы ФП на основе гетероэпитаксиальных структур слоев теллурида кадмия и ртути, выращенных методом молекулярно-лучевой эпитаксии (ГЭС КРТ МЛЭ). Для сравнения параметров фотодиодов на основе $\mathrm{p}$ на $\mathrm{n}$ переходов были изготовлены также образцы фотодиодов на основе $\mathrm{n}$ на $\mathrm{p}$ переходов по традиционной технологии с использованием имплантации ионами $\mathrm{B}^{+}$. После изготовления фотодиодов были исследованы температурные зависимости темновых токов и фототоков. Было обнаружено, что новая технология позволяет работать в режиме ограничения фоном при повышенных температурах до $105 \mathrm{~K}$ для фотодиодов с длинноволновой границей чувствительности 11,2 мкм при 77К (рис.1). Проведен расчет температурной зависимости разности температур эквивалентной шуму (NETD) для ФД с измеренными параметрами, с ограниченной площадью рабочего слоя $\mathrm{A}_{\mathrm{d}}=30 \times 30 \mathrm{m \kappa м}^{2}$ при учете только теплового шума Джонсона - Найквиста и фотонного шума ФД. Использование р-на-n технологии изготовления фотодиодов на основе ГЭС КРТ МЛЭ с длинноволновой границей чувствительности $\lambda_{\text {cut }}=10,3$ мкм, позволяет повысить рабочую температуру примерно на $25 \mathrm{~K}$, а для фотодиодов с длинноволновой границей чувствительности $\lambda_{\text {cut }}=$ 11,2 мкм примерно на 20К без заметного ухудшения NETD (рис.2)

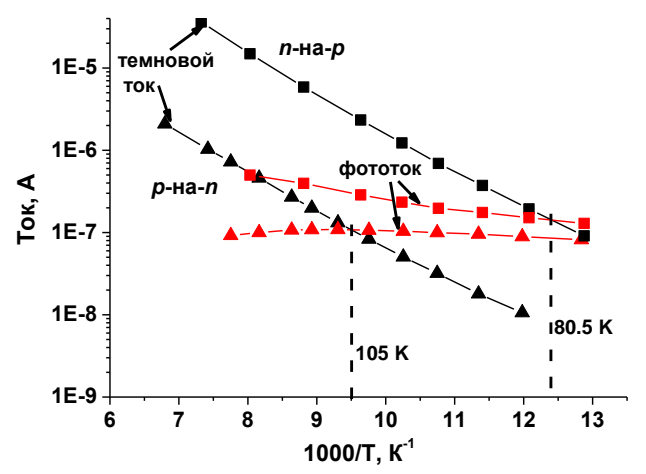

Рис. 1. Темновой ток р-на-n (треугольники) и n-на-р (квадраты) фотодиодов при обратном смещении 50 - 100 мВ. Кривые помеченные красным цветом - температурные зависимости фототока. Штриховыми линиями обозначены температуры начала режима ограничения фоном $\left(\mathrm{T}_{\text {оф}}\right)$.

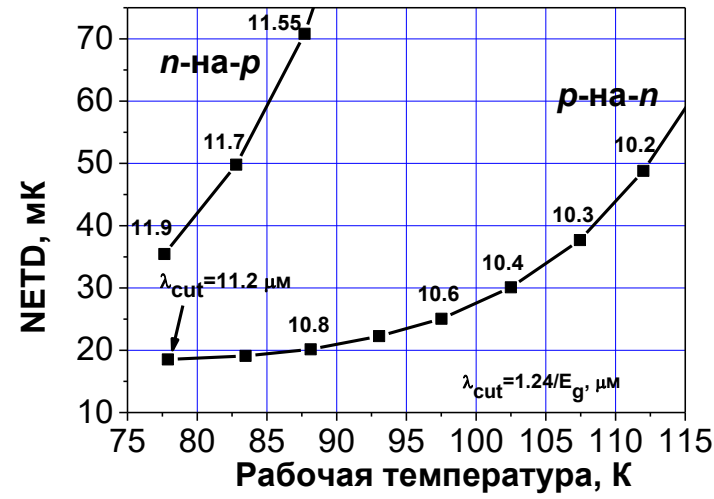

Рис. 2. Расчетная зависимость NETD от рабочей температуры для фотодиодов, изготовленных по технологии $\mathrm{p}$-n и по технологии n-p. Величина длины волны отсечки равна $\lambda_{\text {cut }}=1.24 / \mathrm{E}_{\mathrm{g}}$, мкм, где $\mathrm{E}_{\mathrm{g}}-$ ширина запрещенной зоны, эВ.

Таким образом, использование р-на-n технологии изготовления фотодиодов на основе ГЭС КРТ МЛЭ для спектрального диапазона 8-11 мкм позволяет повысить рабочую температуру примерно на 20 K без заметного ухудшения NETD. Повышение рабочей температуры позволяет повысить рабочий ресурс микрокриогенных систем, снизить их массу и габариты, а также стоимость фотоприемного модуля в целом. 